Canadian Journal of Family and Youth, 5(1), 2013, pp 39-63

ISSN 1718-9748 (c) University of Alberta

http://ejournals.library.ualberta.ca/index/php/cjfy

\title{
Correlates of Help-Seeking Behaviour in Adolescents Experiencing a Recent Negative Life Event
}

\author{
Janie Houle, François Chagnon, Denis Lafortune, Réal Labelle and \\ Katherine Belleville Paquette
}

\begin{abstract}
This study examines the psychological factors associated with formal and informal help-seeking behaviour after a recent negative life event in adolescents 14-17 years old. A sample of 126 adolescents attending secondary schools completed the Life Events Questionnaire (Newcomb), the Beck Depression Inventory, the Temperament and Character Inventory (Cloninger) and the Impulsivity Scale (Barratt). The results indicate that informal help-seeking is more frequent than formal. The factors associated with seeking help from the informal network (friends, parents, siblings, relatives) after the life event were the female gender, living in an intact nuclear family, and reward dependence. Formal help seeking is associated with having sought help from the mother and cognitive impulsivity. Recommendations for increasing adolescents' help-seeking behaviour are suggested.
\end{abstract}

Janie Houle, Ph.D., is professor and researcher in community psychology at the University of Quebec at Montreal, and at the Center for Research and Intervention on Suicide and Euthanasia (CRISE). Her research interests are in suicide prevention, gender differences in health behaviors, and self-management. François Chagnon PhD, is a psychology professor at the University of Quebec at Montreal (UQÀM) and co-director of the Chaire CJM-IU-UQÀM on knowledge application in youth and family services. Involved in youth protection services for 37 years, his researches focus on knowledge transfer, program evaluation and mental health in youths. Denis Lafortune (full professor, School of Criminology, University de Montreal) is particularly interested in the prescription of psychotropic medication to youths in youth centres. He has also turned his attention to mental disorders in inmates in provincial facilities. Finally, he is leading a team investigating effects of the new Youth Criminal Justice Act in the province of Quebec. Réal Labelle, M.Ps., Ph.D., is professor and researcher in clinical psychology at the University of Quebec at Montreal, as well as associate professor in psychiatry at the University of Montreal. He specializes in the study, assessment and psychological treatment of depressive disorders and suicidal behavior. Katherine Belleville-Paquelle, B.Sc. in psychology, is working with children and youth in a community organization Les Chemins du soleil. 
Houle, Chagnon, Lafortune, Labelle, \& Paquette

\section{Introduction}

Help seeking "is about communicating with other people to obtain help in terms of understanding, advice, information, treatment, and general support in response to a problem or distressing experience" (Rickwood, Deane, Wilson \& Ciarrochi, 2005). Help may be requested from informal sources of support, such as family members (parents, siblings, relatives) or peers (friends, classmates). Help may also be sought from the formal help network, consisting of health professionals (physicians, psychologists and social workers) and community-based organizations.

Help seeking is a coping strategy that helps maintain the psychological health of adolescents experiencing difficult events, such as a romantic separation, conflicts with parents and academic problems (Rickwood et. al., 2005; Seiffge-Krenke, 2000). However, many studies suggest that a large percentage of young people do not seek the help they need when they experience problems (Booth, Bernard, Quine, Kang, Usherweed, Alperstein \& Bennett, 2004; Cheung \& Dewa, 2007; Meltzer, Bebbington, Brugha, Farrell, Jenkins \& Lewis, 2000). Approximately one third of young people with a high level of depression, anxiety or psychological distress reported having consulted a health professional about their symptoms (Breton, Légaré, Laverdure \& D’Amours, 2002; Sen, 2004; Zachrisson, Rödje \& Mykletun, 2006).

\section{Contextual Correlates of Help-Seeking Behaviour}

Adolescents generally prefer consulting an informal network, particularly friends, in order to obtain help (Boldero \& Fallon, 1995; Booth et al., 2004; Raviv, Raviv, Vago- 
Gefen \& Fink, 2009; Rickwood et al., 2005; Saunders, Resnick, Hoberman \& Blum, 1994; Schonert-Reichl \& Muller, 1996; Sheffield, Fiorenza \& Sofronoff, 2004), and studies have generally shown that girls are more likely to seek help than boys (Donald, Dower, Lucke \& Raphael, 2000; Garland \& Zigler, 1994; Klineberg, Biddle, Donovan \& Gunnell, 2010; Raviv et. al., 2009; Rickwood et. al., 2005; Sen et al., 2004; Hampel \& Petermann, 2005; Saunders et. al., 1994; Schonert-Reichl \& Muller, 1996; Wu, Hoven, Cohen, Liu, Moore, Tiet, Okezie, Wicks \& Bird, 2001). This difference is seen in help seeking in both the formal and informal networks. As a result, more girls than boys receive treatment for mental disorders (Alexandre, 2008). Many studies also associate level of distress with help seeking: the more that young people experience symptoms of distress, the more likely they are to use outside help (Biddle, Gunnell, Sharp \& Donovan, 2004; Essau, 2005; Leaf, Alegria, Cohen, Goodman, Horwitz \& Hoven, 1996; Zachrisson et. al., 2006; Wu et. al., 2001).

An adolescent's family also appears to have a role to play when young people seek help from the formal network. The frequency at which a young person consults is influenced by the rate at which other members of the family consult, particularly the mother (Cardol, Groenewegen, de Bakker, Spreeuwenberg, van Dijk \& van den Bosch, 2005). In addition, the mother's perception of the problem plays a key role in the process of seeking a consultation with a professional resource (Sayal, 2006; Wu et al., 2001). Furthermore, an American population-based survey found a positive correlation between a young person having spoken about his/her problems with a parent and obtaining formal help (Saunders et. al., 1994), however, this result remains to be replicated in other studies. 
Houle, Chagnon, Lafortune, Labelle, \& Paquette

Even though these studies have provided a better understanding of help seeking behaviour among adolescents, some significant methodological problems limit the generalizability of their results. The first problem is that most of the studies used fictional situations to measure adolescents' intentions to seek help, rather than examine help seeking behaviour in real life situations (Carlton \& Deane, 2000; Garland \& Zigler, 1994; Grinstein-Weiss, Fishman \& Eisikovits, 2005; Klineberg et. al., 2010; Puustinen, Kokkonen, Tolvanen, \& Pulkkinen 2004; Raviv et. al., 2009; Rickwood et. al., 2005; Wilson, Deane, Ciarrochi \& Rickwood, 2005). To our knowledge, only three studies conducted over 15 years ago examined help-seeking behaviour among young people in real-life situations (Boldero \& Fallon, 1995; Saunders et. al., 1994; Schonert-Reichl \& Mueller, 1996).

In the first of these studies, Saunders et. al. (1994) used a survey of students in school $(n=17,193)$ to examine their help-seeking behaviour in the formal network after they experienced a serious problem in the previous year. The factors found to be positively associated with seeking professional help comprised suicidal ideation, race (white), socio-economic status (higher), parents' marital status (separated or divorced) and help seeking in the informal network. In this respect, the study demonstrated that students who approach a family member for help are more likely to obtain formal help than those who approach a friend.

In another study, Boldero and Fallon (1995) asked 1,003 participating students to choose one item in a proposed list of problems (problems with family, interpersonal relationships, health, and education) that had caused them considerable distress during the previous 6 months, then to identify the person from whom they had sought help by 
checking one of the following categories: a friend, a family member, a teacher, an adviser or a physician. The variables most associated with help seeking behaviour were sex (female) and having reported an interpersonal problem. Finally, Schonert-Reichl and Mueller (1996) asked 221 adolescents if they had sought help for an emotional or personal problem in the previous year (without specifying the nature of the problem). The factors that they found associated with seeking help from the informal network were sex (female), age, locus of control (external), and social anxiety. Age, self-esteem, and social anxiety were correlated with seeking help from the formal network.

Even though they had examined help seeking behaviour in the context of a real event experienced by their young participants, none of these studies examined the combined influence of a series of recent negative events on the probability that adolescents will seek help. In fact, beyond the primary event that respondents are asked to take as their point of reference, it is possible that in the months preceding the interview some of these adolescents had experienced a series of negative events that could explain part of their help seeking behaviour. In addition to this shortcoming, the studies did not consider the adolescent's distress level at the time of the interview, nor did they examine the contribution made by personality in the help seeking behaviour.

\section{Personality Correlates of Help Seeking Behaviour}

Few studies have examined the dimensions of personality associated with adolescents' help-seeking behaviour. According to Cloninger's psycho-biological model of temperament and character (Cloninger, Svrakic \& Przybeck, 1993), temperament is 
Houle, Chagnon, Lafortune, Labelle, \& Paquette

genetically determined and is characterized by modes of automatic reactions to stimuli, while character refers to cognitive aggregates developed through one's life experiences. The model includes four dimensions of temperament (novelty seeking, harm avoidance, reward dependence, and persistence) and three characters (cooperativeness, selftranscendence, self-directedness). The link between temperament and help-seeking behaviour remain to be established. However, according to the results of two studies that used samples of adults, reward dependence, which is characterized by a tendency toward intensive responses to social approval signals, may be a dimension of temperament that encourages help seeking. One of the studies found that reward dependence encourages medical students to seek social support (Purper-Ouakil, Michel, Perez-Diaz \& Mouren, 2004), while an American population-based survey found the dimension of temperament to be positively correlated with perceived social support (Elovaino, Kivimäki, Puttonen, Heponiemi, Pulkki \& Keltikangas-Järvinen, 2004). The relationship between reward dependence and help-seeking behaviour among adolescents deserves investigation.

Impulsivity, another important personality trait, has never been associated with help-seeking behaviour among adolescents, yet impulsivity is associated with reduced planning capacity and emotional regulation. It is therefore plausible that impulsivity is an obstacle to help-seeking behaviour among adolescents. Temperament and impulsivity may be factors influencing young people's help-seeking behaviour, yet no empirical studies have explored the strength of these relationships.

\section{Goals of the Present Study}


Little information is available on the factors associated with adolescents' helpseeking behaviour following a recent negative life event. More specifically, we know little about the influence of significant psychological variables, such as temperament and impulsivity, on young peoples' help-seeking behaviour. The goal of the present study is to address at least part of this gap by examining the factors associated with help-seeking behaviour among adolescents in the wake of a significant difficult event in the previous year. More specifically, four hypotheses were proposed:

1. Female gender, level of distress, and the cumulative effect of a series of negative events will be positively associated with help seeking;

2. A 'reward dependence' temperament will be positively correlated with help seeking;

3. Impulsivity will be negatively correlated with help seeking;

4. Having sought help from one's mother will be positively correlated with seeking help in formal network.

\section{Method}

\section{Participants}

The present sample included 126 adolescents ( 87 girls and 39 boys) attending one of seven high schools in Montreal, Canada. Participants met the following inclusion criteria: they were French-speaking, 14 to 17 years of age and reported at least one severely stressful event in the year preceding the interview (index event). The severely stressful life events were: (a) a romantic separation; (b) a major relationship break-up (friend or relative); (c) the death of a loved one; (d) a parental divorce; (e) an academic 
Houle, Chagnon, Lafortune, Labelle, \& Paquette

failure; (f) moving one or more times; (g) parent-adolescent conflicts; (h) embarrassing sexual experiences (homosexuality, an STD, pregnancy, etc.); or (i) any other event that is difficult or is perceived by the young person as "important" or "very important." These events were chosen for their high prevalence among young people 14 to 17 years of age, including suicidal adolescents (Chagnon, 2007). Participants were recruited by advertising in classes of students in Grades 9 to 11.

Measures

Formal and Informal Help Seeking Behaviours

Help seeking behaviour was measured in reference to the most stressful event experienced by the participant in the year preceding the interview (the index event). After having the participant recall the event, the interviewer asked whether he had spoken to any friends or family members about what he had experienced in the days following the event (informal help seeking) and whether he had taken steps to obtain help from professionals or organizations (formal help seeking). The participant had to indicate whom he asked for help.

\section{Life Events Questionnaire (LEQ)}

The LEQ (Newcomb, Huba \& Bentler, 1981) consists of 37 events that respondents can report experiencing during the previous year. They rate the emotional impact of these events from very unhappy (-2) to very happy (+2). A score for negative life events is calculated by adding the number of events that the respondent evaluates as unhappy or very unhappy and weighting it according to the reported level of impact: 1 point for each event evaluated as unhappy and 2 points for each event evaluated as very 
unhappy. The total score may vary from 0 to 74 . The French version (Baron, Joubert \& Mercier, 1991) of the LEQ was used.

\section{Beck Depression Inventory (BDI)}

We used the French version (Bouvard \& Cottraux, 2002) of the BDI-II (Beck, Steer \& Brown, 1996), a 21-item self-reported questionnaire that examines the cognitive, behavioural, affective and somatic symptoms of depression. Each item of the BDI-II is comprised of a series of rank-ordered statements. Each statement is assigned a score from 0 to 3 that reflects the severity of the symptom. Students were asked to circle the number associated with the statement that most accurately describes their feelings during the past two weeks. Responses are summed to yield a total score ranging from 0 to 63 . A BDI-II score from 10 to 18 suggests the presence of a mild depression, from 19 to 29 a moderate depression, and from 30-63 a severe depression. In the current sample, the BDI-II was found to have high internal consistency reliability $(\alpha=.83)$.

\section{Temperament and Character Inventory (TCI)}

The TCI (Cloninger et al., 1993) comprises four dimensions of temperament (novelty seeking, harm avoidance, reward dependence, and persistence) and three dimensions of character (self-directedness, cooperativeness, and self-transcendence). Novelty seeking refers to a tendency to be impulsive, quick-tempered, and extravagant. Harm avoidance is related to being cautious and exhibiting apprehensive worrying. Reward dependence is characterized by sensitivity and a concern about evaluation by others. Persistence involves a tendency toward perseverance despite frustration. Selfdirectedness is defined as being self-accepting and autonomous. Cooperativeness refers 
Houle, Chagnon, Lafortune, Labelle, \& Paquette

to being helpful and compassionate and Self-transcendence appears to be insightful, intuitive, and spiritual. We used the French version (Rigozzi \& Rossier, 2004) short-form with 56 items. The Cronbach's alphas derived from this sample were as follows: novelty seeking $=.55$; persistence $=.69 ;$ harm avoidance $=.73$; self-directedness $=.79$; reward dependence $=.73 ;$ cooperativeness $=.73 ;$ self-transcendence $=.84$.

\section{Barratt Impulsivity Scale-10 (BIS)}

The French version (Baylé, Bourdel, Caci, Gorwood, Chignon, Adès \& Loo, 2000) of the BIS-10 (Patton, Stanford, \& Barratt, 1995) comprises 34 items, with answers in a Likert-scale format ranging from 1 (rarely/never) to 4 (always/almost always). This instrument has 3 sub-scales: non-planning impulsivity (orientation towards the present rather than to the future), motor impulsivity (fast reactions and restlessness), and attentional impulsivity (problems related to concentrating or paying attention). The original BIS-10 was found to be internally consistent and to demonstrate concurrent, criteria, content, and construct validity (Barratt \& Patton, 1983). In our sample, the Cronbach's alphas were: non-planning impulsivity $=.48$; motor impulsivity $=.65$; attentional impulsivity $=.53$.

\section{Procedure}

After obtaining permission from school administrators, students were initially contacted when a research assistant made a short presentation of the project in their classrooms. The students were then given a leaflet explaining the purpose of the study and the nature of their expected participation. The leaflet was accompanied by a brief eligibility questionnaire with questions on gender, age, home address and a checklist of 
severely stressful life events. Students interested in participating filled out the eligibility questionnaire, placed it in a sealed envelope and left it with their teacher. The completed questionnaires were then sent to our research team. Once the answers on the questionnaires had been reviewed, a letter was sent to the parents of all the students who had volunteered to participate and met the selection criteria so that they could authorize their child's participation. All the young people who were eligible for the study and whose parents provided an authorization were contacted by telephone to set a time for a meeting with a member of our research team in order to answer the questionnaires. All the questionnaires were administered to adolescents individually at a time that did not interfere with their class work. All participants were volunteers and received $\$ 10$ for their participation.

\section{Data analysis}

Descriptive statistics were first generated in order to characterize the sample and present the student's help-seeking behaviours after the negative life event. Bivariate analyses (ANOVA and Chi-square) were used to compare participant characteristics according to whether or not they had sought help. Binary logistical regression analyses were then performed to examine the factors associated with formal and informal helpseeking behaviours. All the characteristics for which the bivariate analysis revealed statistically significant differences were included in the regression and then nonsignificant factors were progressively removed.

\section{Results}

Description of the sample 
Houle, Chagnon, Lafortune, Labelle, \& Paquette

Of the 126 students who participated in the study, $69.0 \%$ were girls $(n=87)$. The average age was 15.2 years $(\mathrm{SD}=0.98)$. Half of the participants $(52.4 \% ; \mathrm{n}=66)$ were living in an intact nuclear family and $29.4 \%(n=37)$ were born outside Canada.

\section{Formal and informal help-seeking behaviours}

A high percentage (84\%) of the young people had sought help from their informal networks following the difficult event. The most widely used source of help was friends (61.8\%), followed by the mother (39.3\%) (see Table 1). Help was sought less frequently from the formal network, with only one third (34.1\%) of the sample reporting this behaviour following the difficult event.

Table 1

Formal and Informal Help-Seeking Behaviours from Different Sources

\begin{tabular}{lll}
\hline Variable & $\mathrm{n}$ & $\%$ \\
\hline Informal help seeking & 106 & 84.1 \\
& & \\
Friend & 76 & 61.8 \\
Mother & 42 & 39.3 \\
Father & 15 & 14.0 \\
Siblings & 25 & 23.4 \\
Grand-parents & 5 & 4.7 \\
& 43 & 34.1 \\
Formal help seeking & & 16.8 \\
& 21 & 6.4 \\
School resources (psychologist, teacher, social worker) & 29 & \\
Professional resources in the community (psychologist, & 29 \\
social worker, physician) & 6 & 4.8 \\
Community organization (youth center, helpline) & & \\
\hline
\end{tabular}




\section{Correlates of Help Seeking Behaviours}

The results of the bivariate analyses are shown in Table 2 . They confirm part of our first hypothesis, that girls were more likely to seek help from their informal network

than boys $\left(\chi^{2}[1]=9.39 ; p<0.01\right)$, but no gender difference was observed with respect to the formal network. Higher depression scores $(F[1,124]=6.50 ; p<0.05)$ and a larger number of negative events in the past year $(\mathrm{F}[1,122]=5.74 ; \mathrm{p}<0.05)$ were observed among the adolescents who sought help from the formal network compared to adolescents who had not sought help. This confirmed our hypotheses. However, for a depressive symptomatology and a series of recent negative events, no statistically significant differences were found between those who sought help from their informal networks and those who did not.

Adolescents living in an intact nuclear family were more likely to have sought help from their informal networks than adolescents living in other family structures (single-parent, blended or other) $\left(\chi^{2}[1]=4.77 ; \mathrm{p}<0.05\right)$. In accordance with our hypothesis, a greater percentage of adolescents who sought help from their mothers also sought help from the formal network than those who had not sought help from their mothers $\left(\chi^{2}[1]=8.92 ; \mathrm{p}<0.01\right)$. 
Houle, Chagnon, Lafortune, Labelle, \& Paquette

Table 2

\section{Characteristics of Participants by Help Seeking Behaviour}

\begin{tabular}{llllr}
\hline Characteristic & \multicolumn{2}{c}{ Informal help seeking } & \multicolumn{2}{c}{ Formal help seeking } \\
\cline { 2 - 5 } & Seek help & Did not seek & Seek help & Did not seek \\
& $(\mathrm{n}=106)$ & help $(\mathrm{n}=20)$ & $(\mathrm{n}=43)$ & help $(\mathrm{n}=83)$ \\
\hline Gender, n (\%) & & & & \\
Male & $27(69.2)$ & $12(30.1)^{* *}$ & $10(25.6)$ & $29(74.3)$ \\
Female & $79(90.8)$ & $8(9.2)$ & $33(37.9)$ & $62(62.1)$ \\
Age, mean (SD) & $15.2(0.9)$ & $15.5(1.1)$ & $15.3(0.99)$ & $15.2(0.96)$ \\
Family situation, n (\%) & & & & \\
Intact nuclear family & & & & \\
Other & $60(90.1)$ & $6(9.9)^{*}$ & $22(33.3)$ & $44(66.7)$ \\
& $46(76.7)$ & $14(23.3)$ & $21(35.0)$ & $39(65.0)$
\end{tabular}

Ethnicity, n (\%)

$\begin{array}{lllll}\text { Born in Canada } & 78(87.6) & 11(12.4) & 35(39.3) & 54(60.7) \\ \text { Born outside Canada } & 28(75.7) & 9(24.3) & 8(21.6) & 29(78.4)\end{array}$

Asking help from mother, n (\%)
Yes
$23(54.8) \quad 19(45.2)^{* *}$
No
$17(26.2) \quad 48(73.8)$
$4.5(2.9)$
$3.5(2.6)$
$5.2(3.0)$
$3.9(2.7)^{* *}$
$13.8(8.7)$
$12.4(8.4)$
$16.2(8.5)$
$12.2(8.5)^{*}$

Negative life events, mean (SD)

Depression score, mean (SD) 


\section{Correlates of Help-Seeking Behaviour}

\begin{tabular}{|c|c|c|c|c|}
\hline \multirow[t]{3}{*}{ Characteristic } & \multicolumn{2}{|c|}{ Informal help seeking } & \multicolumn{2}{|c|}{ Formal help seeking } \\
\hline & Seek help & Did not seek & Seek help & Did not seek \\
\hline & $(\mathrm{n}=106)$ & help $(n=20)$ & $(n=43)$ & help $(n=83)$ \\
\hline \multicolumn{5}{|c|}{ Temperament and character, mean (SD) } \\
\hline Novelty seeking & $14.4(3.9)$ & $13.9(5.3)$ & $14.9(4.2)$ & $14.0(4.1)$ \\
\hline Persistence & $19.7(4.6)$ & $17.9(5.9)$ & $19.9(5.0)$ & $19.2(4.7)$ \\
\hline Harm avoidance & $16.4(5.0)$ & $15.3(5.8)$ & $16.8(5.3)$ & $15.6(5.0)$ \\
\hline Directedness & $19.6(5.4)$ & $19.3(6.8)$ & $18.7(5.6)$ & $20.0(5.6)$ \\
\hline Reward dependence & $21.7(5.2)$ & $15.6(5.0)^{* * *}$ & $21.1(5.4)$ & $20.5(5.8)$ \\
\hline Cooperativeness & $22.9(4.7)$ & $21.2(5.1)$ & $22.4(4.9)$ & $22.7(4.8)$ \\
\hline Transcendence & $11.1(6.7)$ & $10.1(7.1)$ & $12.4(6.8)$ & $10.2(6.7)$ \\
\hline \multicolumn{5}{|l|}{ Impulsivity, mean (SD) } \\
\hline Attentional impulsivity & $19.7(6.1)$ & $19.7(6.8)$ & $21.7(6.7)$ & $18.6(5.7)^{* *}$ \\
\hline Motor impulsivity & $15.8(6.8)$ & $14.7(7.0)$ & $17.4(7.4)$ & $14.7(6.2)^{*}$ \\
\hline Non-planning impulsivity & $16.7(5.5)$ & $18.9(6.6)$ & $16.6(5.3)$ & $17.4(5.9)$ \\
\hline
\end{tabular}


Houle, Chagnon, Lafortune, Labelle, \& Paquette

Very few differences were observed in terms of personality. In support of our hypothesis, the only dimension of temperament associated with seeking help is reward dependence, which was less pronounced among respondents who had sought help from their informal networks as compared to those who had not $(\mathrm{F}[1,119]=22.17$; $\mathrm{p}<$ 0.001). This difference was not, however, observed for help sought from the formal network. Cognitive impulsivity $(\mathrm{F}[1,123]=7.38 ; \mathrm{p}<0.01)$ and motor impulsivity $(\mathrm{F}[1$, $123]=4.51 ; \mathrm{p}<0.05)$ were higher among young people who sought help from their formal network, which runs counter to our hypothesis. No relative difference in impulsivity was observed in help seeking from informal networks.

The logistical regression analyses selected three factors associated with seeking help from the informal network (see Table 3) and two associated with seeking help from the formal network (see Table 4). Young women are almost 5 times more likely to seek informal help than young men, and an adolescent living in an intact nuclear family is 4.5 times more likely to seek help from a parent, sibling or friend. Under this model, reward dependence is another factor significantly associated with informal help seeking.

Concerning help sought from the formal network, adolescents who discuss their problem with their mother are 5.3 times more likely to have asked for this type of help. Cognitive impulsivity also makes a significant contribution to the probability of seeking formal help. 
Table 3

Binary Logistic Regression: Characteristics of Participants and Informal Help Seeking Behaviour

\begin{tabular}{lccc}
\hline Variable & OR & $95 \%$ CI & p-value \\
\hline Female gender & 4.87 & 1.47 to 16.12 & 0.01 \\
Living in an intact nuclear family & 4.44 & 1.23 to 16.03 & 0.23 \\
Reward dependence & 1.28 & 1.13 to 1.46 & 0.000 \\
\hline
\end{tabular}

Table 4

Binary Logistic Regression: Characteristics of Participants and Formal Help-Seeking Behaviour

\begin{tabular}{lccc}
\hline Variable & OR & $95 \%$ CI & p-value \\
\hline Asking help from mother & 5.38 & 2.08 to 13.95 & 0.001 \\
Attentional impulsivity & 1.16 & 1.06 to 1.26 & 0.001 \\
\hline
\end{tabular}


Houle, Chagnon, Lafortune, Labelle, \& Paquette

\section{Discussion}

The main purpose of this study was to examine adolescents' help-seeking behaviour after a significant negative event. Our results, like several earlier studies (Boldero \& Fallon, 1995; Booth et. al., 2004; Sheffield et. al., 2004; Raviv et. al., 2009; Rickwood et. al., 2005), confirm that when adolescents are in difficulty, they are more willing to seek help from their informal networks than from health professionals. Our findings also agree with previous studies that found that young women are more inclined than young men to seek help from a parent, sibling or friend. This result may be due to the fact that young men perceive help-seeking behaviour as a sign of weakness, and this runs counter to the image of strength that they must project (Timlin-Scalera, Ponterotto, Blumberg \& Jackson, 2003). Even though our study suggests that fewer boys than girls tend to use formal networks ( $26 \%$ compared to $38 \%$ ), this difference was not statistically significant, probably because our limited sample size. Interventions designed to enhance help-seeking behaviour in adolescents should therefore pay particular attention to these gender differences and specifically address the reluctance of boys to seek help when they experience a problem.

In the informal network, friends are the source of support that is used most often by young people. The decision to seek help from a friend has real consequences on the probability of using professional help, since our results suggest that parents could facilitate the search for formal help by young people. In fact, seeking help from the formal network is much more common among young people who speak to their mothers about their negative event. Even though our transversal design does not allow us to reach any conclusions on the order in which help-seeking behaviours occur, it is possible that 
the young people who spoke to their mothers about the event then took steps, either with or without her help, to obtain more formal help. In this sense, our results tend to confirm the hypothesis proposed by certain models that parental recognition of a problem acts as a crucial filter in the trajectory by which children and adolescents obtain mental health services (Goldberg \& Huxley, 1980; Verhulst \& Koot, 1992). Indeed, a recent study has shown that young people who turn to a parent for help with an emotional problem are more intent on using mental health services, while those who perceive that their parents disapprove of this type of services show less intent (Chandra \& Minkovitz, 2006). Furthermore, the role of parents with respect to the problem experienced by a young person may go beyond seeking help, and also foster maintenance of the professional relationship over time. Shirk and Karver (2003), at the end of a meta-analysis covering 49 studies, concluded that the positive participation of one or both parents is one of the most important dimensions for establishing a work alliance with adolescents in distress. All these data underscore the crucial contribution made by parents in helping young people gain access to professional help. Since adolescents naturally tend to seek help nearby (friends, family) and see the help of mental health professionals as a last resort, it is important to improve young people's perceptions of and access to the formal help network. A recent study underscores how young people in emotional difficulty do not trust health professionals (Leavey, Rothi \& Paul, 2010). Interventions need to be developed to address this problem, and, if they are to be effective, parents will need to be involved.

Another goal of this study was to examine the link between the temperament and character of an adolescent and help-seeking behaviour following a difficult event. In our 
Houle, Chagnon, Lafortune, Labelle, \& Paquette

sample, the only dimension of temperament associated with help-seeking behaviour is reward dependence, which is characterized by an intense response to reward signals such as social approval. A link between this temperament dimension and help-seeking behaviour had already been observed among adults (Purper-Ouakil et. al., 2004; Elovaino et. al., 2004), but never among young people. In clinical terms, we propose as an explanation that when adolescents face challenging experiences, those who seek social approval, are sensitive to rejection, have strong emotional responses and seek gratification will be more inclined to seek help. These results suggest that the professionals who help adolescents risk encountering many who have a certain reward dependence (e.g.: social approval and actualization). Yet other adolescents who do not have this trait may have had to deal with events that are as difficult. Since they do not consult when their distress level is high, they represent a challenge for effective outreach. Our results need to be replicated in larger samples of young people who are facing major emotional or relational problems.

Finally, our study indicates that cognitive impulsivity increases the probability that an adolescent will seek help in the formal network. This is an unexpected and unprecedented result, since, to our knowledge, no previous study has examined the relationship between impulsivity and young peoples' help-seeking behaviour. Adolescents who make quick decisions and who have difficulty concentrating and thinking calmly may have more difficulty solving problems on their own and will more quickly seek professional help. On the other hand, parents who know their child well and who fear that the child's impulsivity will cause him to make poor decisions may be more inclined to help him find resources than if they believe that their child is capable of 
making well-considered decisions. In the context of seeking help for affective problems, it is therefore possible that impulsivity is associated with poorer problem resolution strategies, less capacity for emotional regulation, and, therefore, a greater need for help. Professionals therefore risk seeing many adolescents who present with cognitive impulsivity, but since these young people have problems thinking calmly, they may present a challenge in terms of maintaining the therapeutic relationship and allowing their professional to continue the follow-up. Future studies will need to verify this hypothesis.

\section{Limitations}

These results came from a convenience sample of limited size, consisting solely of young residents of the Montreal urban area, so they are not generalizable to young people from rural areas. Furthermore, participants were recruited on the basis of a recent difficult event that they themselves had evaluated as serious and significant. However, we had no other objective measure of the seriousness of the events, which would have allowed us to keep only young people reporting serious events in the sample. Our sample consisted mainly of young people in good psychological health, as can be seen in the very low levels of depressive symptomology. As a result, our results cannot be generalized to young people living with serious mental health problems. It would be interesting to see a future study compare clinical populations with normal populations. In spite of these weaknesses, our study has examined help-seeking behaviour by young people in real situations. It has also explored relationships between personality, impulsivity and helpseeking behaviour among young people. We now have a better understanding of the factors associated with help seeking-behaviour following a difficult event, and interesting intervention and research avenues have been identified. 
Houle, Chagnon, Lafortune, Labelle, \& Paquette

\section{Acknowledgements}

We wish to express our sincere appreciation to all adolescents who participated in this study. We would also like to thank Julie Bouchard, Fabien Besner and Préscilla Labelle for their assistance in data collection and entry. This study was funded by the Social Sciences and Humanities Research Council of Canada. 


\section{References}

Alexandre, P. (2008). 'Mental health care for youth: predictors of use are not always the same as predictors of volume.' Social Science Journal, 45(4) : 619-632.

Baron, P., Joubert, N., \& Mercier, P. (1991). 'Situations stressantes et symptomatologie dépressive chez les adolescents.' Revue européenne de psychologie appliquée, $41: 173-179$.

Barratt, E., \& Patton, J. H. (1983). 'Impulsivity: Cognitive, behavioral, and psychophysiological correlates.' In M. Zuckerman (Ed.), Biological bases of sensation seeking, impulsivity, and anxiety. (pp. 77-116). Hillsdale, NJ: Lawrence Erlbaum Associates.

Baylé, F. J., Bourdel, M. C., Caci, H., Gorwood, P., Chignon, J. M., Adès, J., \& Loo, H. (2000). 'Structure factorielle de la traduction française de l'échelle d'impulsivité de Barratt (BIS-10)' (Factor structure of the French translation of the Barratt Impulsiveness Scale). Revue Canadienne de Psychiatrie, 45(3), 156-165.

Beck, A. T., Steer, R. A., Brown, G. K. (1996). Manual for Beck Depression InventoryII._San Antonio, TX: Psychological Corporation.

Biddle, L., Gunnell, D., Sharp, D., \& Donovan, J. L. (2004). 'Factors influencing help seeking in mentally distressed young adults: a cross-sectional survey.' British Journal of General Practice, 54, 248-253.

Boldero, J., \& Fallon, B. (1995). 'Adolescent help-seeking: what do they get help for and from who?' Journal of Adolescence, 18, 193-209.

Booth, M. L., Bernard, D., Quine, S., Kang, M. S., Usherwood, T., Alperstein, G., \& Bennett, D. (2004). 'Access to health care among Australian adolescents young people's perspectives and their sociodemographic distribution.' Journal of Adolescent Health $, 43,97-103$.

Bouvard, M., \& Cottraux, J. (2002). 'Inventaire de dépression de Beck-II.' In M. Bouvard et J. Cottraux, Protocoles et échelles d'évaluation en psychiatrie et en psychologie (pp. 185-186). Paris: Masson.

Breton, J.J., Légaré, G., Laverdure, J., D’Amours, Y. (2002). « Santé mentale» dans Enquête sociale et de santé auprès des enfants et des adolescents québécois 1999, Québec, Institut de la statistique du Québec, chapitre 19, p. 433-446.

Cardol, M., Groenewegen, P. P., de Bakker, D. H., Spreeuwenberg, P., van Dijk, L., \& van den Bosch, W. (2005). 'Primary care. Shared help seeking behaviour within families: a retrospective cohort study.' British Medical Journal, 330, 882-884.

Carlton, P. A. \& Deane, F. P. (2000). 'Impact of attitudes and suicidal ideation on adolescents' intentions to seek professional psychological help.' Journal of Adolescence, 23, 35-45.

Chagnon, F. (2007). 'Coping mechanisms, stressful events and suicidal behavior among youth admitted to juvenile justice and child welfare services.' Suicide and Life Threatening Behavior, 37(4), 439-452.

Chandra, A., \& Minkovitz, C.S. (2006). 'Stigma starts early: Gender differences in teen willingness to use mental health services.' Journal of Adolescent Health, 38 754e1-754e8.

Cheung, A. H. \& Dewa C. S. (2007). 'Mental health service use among adolescents and young adults with major depressive disorder and suicidality.' Canadian Journal of Psychiatry, 52(4), 228-232. 
Houle, Chagnon, Lafortune, Labelle, \& Paquette

Cloninger, R. C., Svrakic, D. M., \& Przybeck, T. R. (1993). 'A psychobiological model of temperament and character.' Archives of General Psychiatry, 50(12), 957-990.

Donald, M., Dower, J., Lucke, J., \& Raphael, B. (2000). The Queensland Young People's Mental Health Survey Report. Brisbane: Center of Primary Health Care, School of Population Health and Department of Psychiatry, University of Queensland.

Elovainio, M., Kivimäki, M., Puttonen, S., Heponiemi, T., Pulkki, L. \& KeltikangasJärvinen, L. (2004). 'Temperament and depressive symptoms: a population-based longitudinal study on Cloninger's psychobiological temperament model.' Journal of Affective Disorders, 83, 227-232.

Essau, C.A., (2005). 'Frequency and patterns of mental health services utilization among adolescents with anxiety and depressive disorders.' Depression and Anxiety, 22, 130-137.

Garland, A. F., \& Zigler, E. F. (1994). 'Psychological correlates of help-seeking attitude among children and adolescent.' American Orthopsychiatric Association, 64 (4), 586-593.

Goldberg, D. \& Huxley, P. (1980). Mental illness in the community: the pathway to psychiatric care. London, NY: Tavistock Publications.

Grinstein-Weiss, M., Fishman, G., \& Eisikovits, Z. (2005). 'Gender and ethnic differences in formal and informal help seeking among Israeli adolescents.' Journal of Adolescence, 28, 765-779.

Hampel, P., \& Petermann, F. (2005). Age and Gender Effects on Coping in Children and Adolescents. Journal of Youth and Adolescence, 34(2), 73-83.

Klineberg, E., Biddle, L., Donovan, J. \& Gunnell, D. (2010). 'Symptom recognition and help seeking for depression in young adults: a vignette study.' Social Psychiatry and Psychiatric Epidemiology. Retrieved June 21, 2010, from http://www.springerlink.com/content/07805519w5307687/fulltext. html

Leaf, P. J., Alegria, M., Cohen, P., Goodman, S. H., Horwitz S. M., Hoven, C. W., et al. (1996). 'Mental health service use in the community and schools: results from the four-community MECA study.' Journal of the American Academy of Child and Adolescent Psychiatry, 35, 889-897.

Leavey, G., Rothi, D., Paul, R. (2010). 'Trust, autonomy and relationships: The helpseeking preferences of young people in secondary level schools in London (UK).' Journal of Adolescence, 1-9 in press.

Meltzer, H., Bebbington, P., Brugha, T., Farrell, M., Jenkins, R., \& Lewis, G. (2000). 'The reluctance to seek treatment for neurotic disorders.' Journal of Mental Health, 9(3), 319-327.

Newcomb, M. D., Huba, G. J., \& Bentler, P. M. (1981). 'A Multidimensional Assessment of Stressful Life Events among Adolescents: Derivation and Correlates.' Journal of Health and Social Behavior, 22, 400-415.

Patton, J. H., Stanford, M. S., \& Barratt, E. S. (1995). 'Factor structure of the Barratt impulsiveness scale.' Journal of Clinical Psychology, 51, 768-774.

Pulkkinen, L. (1996). 'Female and male personality styles: A typological and developmental analysis.' Journal of Personality and Social Psychology, 70, 1288-1306.

Purper-Ouakil, D., Michel, G., Perez-Diaz, F., \& Mouren, M.-C. (2004). 'Influence des traits de tempérament et du contexte sur le choix des stratégies de coping dans 
une population d'étudiants.' Annales Medico Psychologiques, 162(3), 203-208.

Puustinen, M., Kokkonen, M., Tolvanen, A., \& Pulkkinen, L. (2004). 'Children's help seeking and impulsivity.' Learning and Individual Differences, 14, 231-246.

Raviv, A., Raviv, A., Vago-Gefen, I., \& Fink, A. S. (2009). 'The personal service gap: Factors affecting adolescents' willingness to seek help.' Journal of Adolescence, 32, 483-499.

Rickwood, D., Deane, F. P., Wilson, C. J., \& Ciarrochi, J. (2005). 'Young people's helpseeking for mental help problems.' Australian e-Journal for the Advancement of Mental Health, 4_The mental health of young people in Australia (3), 218-251.

Rigozzi, C. \& Rossier, J. (2004). 'Validation d'une version abrégée du TCI (TCI-56) sur un échantillon de jeunes fumeurs et non-fumeurs.' Annales Médico Psychologiques, 162, 541-548.

Saunders, S.M., Resnick, M.D., Hoberman, H.M. \& Blum, R.W., (1994). 'Formal helpseeking behaviour of adolescents identifying themselves as having mental health problems.' Journal of the American Academy of Child and Adolescent Psychiatry, 33(5), 718-728.

Sawyer, M .G, Arney, F. M., Baghurst, P. A., Clark, J. J., Graetz, B. W., Kosky, R. J., et al. (2000). The mental health of young people in Australia. Cranberra, Australia: Publication Production Unit, Commonwealth Department of Health and Aged Care.

Sayal, K. (2006). 'Annotation: Pathways to care for children with mental health problems.' Journal of Child Psychology and Psychiatry, 47(7), 649-659.

Schonert-Reichl, K. A., \& Muller, J. R. (1996). 'Correlates of Help-Seeking in Adolescence.' Journal of Youth and Adolescence, 25(6), 705-731.

Seiffge-Krenke, I. (2000). 'Causal links between stressful events, coping style, and adolescent symptomatology.' Journal of Adolescence, 23, 675-691.

Sen, B., (2004). 'Adolescent propensity for depressed mood and help seeking: Race and gender differences.' The Journal of Mental Health Policy and Economics, 7, 133-145.

Sheffield, J. K., Fiorenza, E., \& Sofronoff, K. (2004). 'Adolescents' Willingness to Seek Psychological Help: Promoting and Preventing Factors.' Journal of Youth and Adolescence, 33(6), 495-507.

Timlin-Scalera, R.M., Ponterotto, J.G., Blumberg, F.C. \& Jackson, M.A. (2003). 'A grounded theory study of help-seeking behaviours among white male high school students.' Journal of Counseling Psychology, 50(3), 339-350.

Verhulst, F. C. \& Koot, J. M. (1992). Child psychiatric epidemiology: concepts, methods and findings. Beverly Hills, CA: Sage Publications.

Wilson, C. J., Deane, F. P., Ciarrochi, J., \& Rickwood, D. (2005). 'Measuring helpseeking intentions: Properties of the General Help-Seeking Questionnaire.' Canadian Journal of Counselling, 39(1), 15-28.

Wu, P., Hoven, C.W., Cohen, P., Liu, X., Moore, R.E., Tiet, Q., Okezie, N., Wicks, J. \& Bird, H.B., (2001). 'Factors associated with use of mental health services for depression by children and adolescents.' Psychiatric Services, 52(2), 189-195.

Zachrisson, H. D., Rödje, K., \& Mykletun, A. (2006). 'Utilization of health services in relation to mental health problems in adolescents: A population based survey. Biomed Central Public Health, 6(34), 34-40. 